\title{
Crónica narrativa latinoamericana actual: los límites de lo real*
}

\author{
Patricia Poblete Alday ${ }^{* *}$
}

\section{Resumen}

A partir de la crónica que tematiza la violencia contemporánea en América Latina - especialmente en México- proponemos aquí una reflexión acerca de la representación y la concepción de lo real que posibilita este género. Dicha reflexión se articula en dos etapas: en la primera veremos cómo las condiciones externas, sociopolíticas, determinan y horadan la referencialidad del texto, mientras que en la segunda nos centraremos en el uso de recursos formales que colaboran en el cuestionamiento de los límites de lo real y de lo posible.

Palabras clave: violencia, mal, crónica, realidad, relato fantástico.

\section{Current latin american Crónica: limits of reality}

\begin{abstract}
In this text we propose a reflection on the ways of representation and conception of the reality, based on narrative Crónica that relate the contemporary violence in Latin America, particularly in Mexico. First, we'll see how external, sociopolitical factor determine and corrupt the referenciality of the text, and in a second stage our attention will be focused on formal strategies used to questioning the limits of the reality and the possible.
\end{abstract}

Keywords. Violence, Evil, Crónica, Reality, Fantastic tale.

Este texto forma parte de los proyectos Fondecyt Regular $N^{\circ} 1160027$, del cual la autora es investigadora responsable, y Fondecyt Regular $\mathrm{N}^{\circ} 1170993$, del cual es coinvestigadora.

* Chilena. Doctora en Literatura por la Universidad Complutense de Madrid. Académica de la Universidad Academia de Humanismo Cristiano, Santiago, Chile.ppoblete@academia.cl 


\section{Introducción}

Uno de los efectos colaterales más relevantes de la caída de los metarrelatos en la posmodernidad (Lyotard 1994) en el ámbito de los estudios literarios, fue el reforzamiento del discurso referido a la porosidad de los límites genéricos y el debate crítico en torno al canon. La sospecha -en sus diversos matices, desde el tibio descreimiento hasta el franco revisionismo - se instaló como una suerte de "espíritu de época" que apuntaba, antes que todo, al estatus mismo de lo real. Complementariamente desde las ciencias del comportamiento, el constructivismo señaló que el mundo no es un dato externo y a priori, sino que vamos construyéndolo desde nuestra propia experiencia, y desde allí no habría razón para pensar que las estrategias lingüísticas o estilísticas que usamos para construir la realidad dentro de la ficción son distintas de las que utilizamos para construir la realidad dentro de la no-ficción: en ambos casos se trata de estrategias para producir sentido, determinadas biológicamente y convencionalizadas socialmente (Schmidt 1997). Con ello, la tradicional división que asociaba la literatura con la ficción, y al periodismo con la realidad, acabó por perder legitimidad.

Así como en tiempos pasados, la crónica narrativa escenifica hoy esta tensión entre realidad y ficción, desde el discurso comprendido ya no como una instancia inocente que transparenta la realidad, sino como parte de los dispositivos socioculturales que vehiculan y revelan nuestro conocimiento primario (Jäger 2003). Y es que, si en el Modernismo con la crónica se disputó el lugar del reportero dentro del campo cultural (Ramos 1989; Rotker 2005), hoy tanto el periodismo como la literatura se cuestionan la validez del criterio de realidad y los discursos oficiales que lo establecen y perpetúan.

Antes de continuar, es necesario precisar lo que comprendemos por “crónica narrativa”, ya que se suele agrupar bajo esta etiqueta a piezas tan disímiles como las cartas de los conquistadores, una nota informativa, un registro historiográfico o una columna de opinión. Comprendemos por crónica un texto periodístico, que se basa en los criterios de lo noticioso ${ }^{1}$, pero remonta el mero afán informativo mediante cuatro estrategias (Poblete Alday, “La crónica...” 2018):

Carl Warren (1975) identificó los elementos que componían lo "noticioso": actualidad, proximidad, prominencia, curiosidad, conflicto, suspense, emoción y consecuencias. 
a. La inserción de lo coyuntural en una corriente de acciones continua y significativa, lo que nos permite conectar explicativamente hechos noticiosos y también comprenderlos como manifestaciones o "síntomas" de un complejo entramado de factores, que son los que constituyen los "antecedentes" y el "contexto". Es lo que hace, por ejemplo, Ryszard Kapuściński (2006) en El Sha o la desmesura del poder: situar hechos concretos (aquellos que desembocaron en la caída de Mohamad Reza Pahlavi, en 1979) dentro del devenir histórico-universal (en este caso, la lógica y dinámica de las revoluciones), de modo tal que aquellos pueden ser comprendidos más allá de su funcionalidad inmediata.

b. La apelación a constantes humanas universales, por lo que en estos relatos se distinguen claramente las "historias" - o el encadenamiento de hechos - de las temáticas que le subyacen. Así, por ejemplo, en crónicas como El empampado Riquelme, de Francisco Mouat (2001), o Perdido (missing), de Alberto Fuguet (2007), el seguimiento de una pista noticiosa termina revelando el clásico motivo de la búsqueda del padre.

c. El enfoque de la realidad se hace desde el prisma propio y personal del cronista. El Yo del cronista siempre está presente, como "una situación de la mirada" (Caparrós 2015, 502) antes que como pronombre. En consecuencia, y en oposición a lo que sucede en el periodismo informativo, en la crónica narrativa es dable distinguir al autor (persona) del narrador (entidad textual). Es lo que sucede, por ejemplo, cuando Elena Poniatowska asumía el rol de "niña fresa" para interpelar a sus entrevistados, logrando piezas notables como la entrevista a Cantinflas incluida en el segundo tomo de Todo México (1995).

d. El desarrollo del aspecto estético de la materialidad textual, utilizando recursos narrativos tradicionalmente asociados a la ficción y vetados de la economía de la nota periodística informativa. Este aspecto, como subrayaremos más adelante, no es independiente, sino que deriva de una toma de posición ética ante lo narrado. Por ejemplo: la estructura de mosaico que elige Elena Poniatowska para La noche de Tlatelolco (1971) revela una posición política ante lo narrado; todos los testimonios tienen la misma importancia (aquí las palabras de Octavio Paz valen lo mismo que las de una actriz desconocida, o de un estudiante secundario), y la colectividad aparece no como una 
masa indiferenciada, sino como suma de individualidades. Las voces e historias fragmentadas replican la fuerza de las manifestaciones callejeras no solo en el nivel del contenido, sino también desde el porqué de su ensamblaje.

En las siguientes páginas nos proponemos analizar cómo cierta crónica narrativa que se escribe y publica hoy en América Latina —en particular, aquella que tematiza la violencia cotidiana en manifestaciones como el narcotráfico, las pandillas y la crisis migratoria en América del Norte-colabora en este cuestionamiento de los límites de lo real, propiciando una discusión que atañe tanto a la teoría literaria como a los criterios éticos sobre los cuales asentamos nuestra convivencia social. La primera estrategia para ello se sitúa a nivel semántico; la segunda atañe a la estructura misma del escrito y a los recursos formales que colaboran en su composición.

\section{La verdad torcida}

En el periodismo de nuestro continente, Rodolfo Walsh fue pionero en el desmontaje de las verdades oficiales, revelando las inconsistencias y contradicciones de un aparato comunicacional cómplice del régimen dictatorial de Pedro Eugenio Aramburu. Con Operación masacre (1957) ${ }^{2}$, el argentino probó tempranamente que un buen periodismo de investigación no es incompatible con una prosa esmerada y de profundo espesor estético.

Buena parte de la crónica actual que analizamos se orienta también a mostrar cómo los poderes — sean institucionales o fácticos- maquillan o tuercen la realidad según sus intereses, creando verdaderos montajes que se presentan como verdades desde el discurso de los medios de comunicación. No hablamos de la tan manoseada "posverdad" —noción que implica una manipulación emocional de hechos verificables - sino del falseamiento consciente de evidencia con miras a construir una visión distorsionada de la realidad.

Tres textos de cronistas mexicanos ilustran de forma clara este proceso y su denuncia: "Bajo el ondear de la bandera” (2015), de Daniela Rea; “Las

\footnotetext{
Publicado por entregas en el semanario bonaerense Mayoría, de mayo a julio de 1957. La primera edición en libro es de 1957 (Ed. Sigla) Ediciones posteriores (Continental, 1967 y Eds. de la Flor, 1984) suman expedientes oficiales del caso. La edición definitiva es de 2011, también del sello de la Flor.
} 
jaulas de la justicia” (2015), de Héctor de Mauleón; y “Veracruz se escribe con zeta" (2018), de Fernanda Melchor. En el primero de ellos se narra la historia de Miriam, una mujer a la cual el gobierno federal le achaca delitos (narcotráfico, principalmente) que ella no ha cometido, en un claro intento de inventar culpables invisibles para librar a los poderosos. La bandera mexicana - símbolo de unidad y protección- se revela aquí como una farsa, tan evidente y rotunda como la que montan los oficiales, y que deriva en torturas, violaciones y en la firma forzada de una declaración autoinculpatoria. En el segundo texto, el sistema judicial se revela como una construcción kafkiana y perversa, en el proceso que continúa luego de las detenciones arbitrarias y que se condensa en un interrogatorio prototípico:

— ¿Cómo lo mataste?

-Yo no lo maté.

-Ah, tú no lo mataste. Entonces ¿por qué te acusan? ¿Por qué le das vueltas a las cosas? Contéstame cómo lo mataste.

-Le digo que no lo maté.

-Contéstame sí o no.

- No voy a inventar algo porque usted me lo pide. Yo no lo maté. No he matado a nadie. (61)

La tercera crónica mencionada, la de Melchor, se enfoca en la manipulación de la realidad desde el narcotraficante, a través de la fuerza y el miedo. Tras la irrupción de unos sujetos armados en una discoteca para sacar arrastrando a un muchacho, este es golpeado en la calle, a vista de todos, hasta quedar inconsciente. Entonces los hombres lo suben a una camioneta y se lo llevan. "Dentro del antro todos tenían cara de espanto, menos los narcos de la mesa junto a la pista", indica la narradora (153); nadie se mueve, hasta que uno de ellos, "un tipo imponente, con el pelo cortado a cepillo, se levantó de su asiento y, sin dirigirse a nadie en particular, gritó que se calmaran todos, que ahí no había pasado nada" (154). El sujeto agrega, desafiante: “¿O qué, alguien vio algo?”3 (154), antes de que toda la concurrencia huya en estampida.

Periodistas como Diego Enrique Osorno (2012) el asesinado Javier Valdez (2017) han dado cuenta de esta presión sobre los medios de comunicación, y del afán tanto del gobierno como de los cárteles para

Cursivas en el original. 
incidir de forma sustantiva en la agenda noticiosa. El primero señala como consecuencias la eliminación de las firmas individuales en los textos publicados, la falta de información recolectada y analizada por los propios medios, y la reproducción textual de la información proveniente de los grupos enfrentados (294-295). El segundo señaló la necesidad de la autocensura para no perder la vida en el ejercicio de la profesión; en este sentido la consideró un ejercicio de sobrevivencia y no de control político:

Uno se siente como un funámbulo, un acróbata del periodismo: haciendo malabares para no quedarse callado, guardar silencio. Y uno grita en los mítines, las protestas, 'no nos callarán'. En realidad [los narcos] ya lo hicieron. Ya entraron a la redacción y nos callaron. A medias o totalmente, como en Tamaulipas o en Sinaloa o en Chihuahua. Ya mandan y no somos nosotros los que tecleamos en las computadoras a la hora de hacer las notas, son ellos los que eligen las letras, las palabras, los párrafos y fotos de nuestras historias. (339)

En ambos casos enfrentamos la paradoja de un periodismo que no relata la realidad (comprendida, grosso modo, como una sucesión de hechos concretos y asociados a una causalidad clara), sino que la emborrona o, en el mejor de los casos, la refleja en su misma estructura: en lo que calla más que en lo que dice. La lectura del periódico en estas sociedades da cuenta, antes que todo, de la imposibilidad de generar un discurso verosímil sobre la realidad inmediata, y nos demanda en cuanto lectores - no solo un conocimiento claro y actualizado del contexto, sino que también nos previene acerca de la inconveniencia de suspender demasiado pronto la incredulidad ante un género que se supone "referencial".

Lo que en estas sociedades sí se pierde, en cambio, es la capacidad de asombro. La periodista Marcela Turati (2011) indica que la muerte a granel es noticia en México hasta que deja de ser algo anormal. "Cuando la violencia compite contra sí misma y se habitúa a romper su propio récord, deja de ser noticia. Por eso, algunos periódicos solo cuentan los asesinatos masivos cuando los muertos son 10 o más" (47). Esto incide, directa y claramente, en nuestra concepción de lo real, por lo que, ante la imposibilidad de informarse de manera completa y fiable desde los medios de comunicación institucionalizados, la ciudadanía ha preferido recurrir a las redes sociales, y a las voces de los propios ciudadanos de 
a pie que testifican "lo que las autoridades no quisieron reconocer y los periodistas no pudieron informar" (252).

A diferencia de lo ocurrido en países bajo dictadura, donde el control de la información está centralizado y el acceso a ella restringido, aquí no existe una entidad única que regule este flujo, sino múltiples enunciantes con intereses muchas veces contrapuestos (los distintos cárteles, pandillas, instituciones de gobierno, etc.) De ahí la discordancia de versiones, las inconsistencias, las pruebas, los huecos que el discurso va dejando en la trama de la realidad y que son, menos que evidencia de una reconstrucción mal hecha, prueba clara de la impunidad de quienes la encargan.

En la práctica, sin embargo, no hay engaño: todos saben que las fuentes oficiales maquillan la realidad; todos saben que los narcos imponen su versión de los hechos a los medios; todos saben que estos cuentan mucho menos de lo que se sabe, y que se sabe tanto menos aún de lo que sucede. Nadie cree en la "realidad paralela" (Turati 238) que construye el relato periodístico bajo amenaza, lo que tampoco significa que dejemos de creer completamente en la labor informativa ni en la buena fe con la que los reporteros hacen su trabajo; tampoco que pasemos a considerar al periódico como un producto derechamente "ficcional". Lo que sucede, más bien, es que así como han surgido nuevas palabras para nombrar el horror ("entambados", "levantados", "sicariar", "pozoleado", etc.) el contexto también nos demanda nuevas formas de leer lo noticioso, situadas a medio camino entre lo real/referencial y lo irreal/ficcional. Así como el periodista debe saber qué parte de su texto cercenar para seguir con vida, el lector debe aprender a identificar en las noticias aquello que es cierto de aquello que no lo es; a interpretar opciones editoriales y a leer entre líneas aquello que se insinúa porque no puede ser dicho directa ni explícitamente.

Informarse se vuelve entonces un ejercicio complejo, que va más allá de la simple comprensión lectora y el conocimiento esencial del contexto; y nos demanda habilidades más finas, como identificar el peso de un eufemismo ("las instituciones han sido omisas en su actuar", "hay integraciones irregulares de las averiguaciones previas", "la entrega de la información se ha dilatado", etc.); saber cuándo un cliché deja de ser una frase hecha para convertirse en la única forma de describir aquello a lo que se refiere ("la maldad encarnada", "una modesta muestra de la orgía de la muerte", "tiene ante sí el rostro del horror", “cifras aterradoras”, 
"esto fue una carnicería", etc.) o interpretar adecuadamente los vacíos, como el que refiere una conductora de televisión en la crónica "Los días de plomo", de Héctor de Mauleón (2015). Cuando los narcos secuestran a dos periodistas, amenazando con matarlos si no se transmite un reportaje que beneficia a su organización, el Canal 2 opta por suspender su transmisión y dejar la pantalla en negro. Dice la presentadora:

Irnos del aire era una forma de decir que estaba pasando algo muy grave en México. Era una forma de decirlo sin decirlo, porque no queríamos poner en riesgo la vida de los reporteros. El objetivo no era salir a hacer un programa que tratara de otras cosas: poner la pantalla en negro tenía por objeto provocar un gran impacto, decirle al Estado que así no era posible hacer periodismo, decirles a los narcos la gravedad de lo que estaban haciendo. (164)

En uno de los extremos críticos de este enmascaramiento de la realidad, el escritor y académico Oswaldo Zavala (2018) llega a denunciar que el propio fenómeno del narco "no existe". Tras lo controversial del título de su ensayo - en el que es fácil ver, por lo demás, una estrategia editorial- sus argumentos resultan bastante atendibles: el narco, así como se lo presenta, no sería sino una "invención discursiva $a^{4}$ de una política estatal que responde a intereses geopolíticos específicos" (230). En otras palabras, el narco no operaría de forma autónoma y por sobre el Estado, sino supeditado a él y en connivencia con la elite mexicana y las empresas transnacionales, orientadas básicamente a explotar las zonas ricas en hidrocarburos. La "guerra entre cárteles" no sería, entonces, más que una invención fabricada y diseminada a través de diversos productos culturales - crónicas, novelas, series de televisión, ensayos académicos...-para desplazar a la población de esos territorios. Siguiendo a Alan Badiou, Zavala identifica una correspondencia exacta entre los discursos periodísticos y literarios, ya que ambos se construirían sobre un imaginario común, aquel diseminado por el poder oficial, que carece de referente real y se afinca únicamente en lo simbólico, produciendo una mitología de la violencia despolitizada y acrítica, que se condensa en el cliché del narco con botas tejanas, sombrero y camisa de diseñador. 


\section{Del sueño a la pesadilla}

La segunda forma por la cual esta crónica cuestiona el estatus de lo real es mediante el recurso a un motivo clásico de la literatura fantástica: la continuidad entre el sueño y la vigilia (Carilla 1968; Caillois 1970), que dramatiza la irrupción de un orden sobre el otro, y la incapacidad (temporal, al menos) de reconocer sus límites.

La crónica "Insomnio" (2018), de Fernanda Melchor, proporciona un buen ejemplo de ello. El texto se abre con el relato del sueño que tuvo una mujer, Rita, en el que caminaba desnuda por un jardín inmenso hasta que un platillo volador se posaba sobre ella, haciendo un ruido "como un motor hecho de carne" (131):

La señora Rita despertó en ese momento, pero el ruido no cesó. Su esposo acababa de levantarse de la cama y abría la puerta del cuarto. Doña Rita le gritó que no saliera pero era tal el estruendo que don Manolo no alcanzó a escucharla; ella lo siguió con las piernas tambaleantes. Parecía que un avión caería sobre la casa, a juzgar por el clamor. Doña Rita no estaba del todo segura de haber despertado del sueño, y corrió al cuarto de Paulito para asegurarse de que no lo hubieran secuestrado los extraterrestres. (131-132)

Por medio de este recurso, se ilustra cómo la desmesura de la violencia cotidiana revela aquellas aristas más oscuras de la realidad que nos esforzamos por mantener ocultas bajo la pátina de la razón y la civilidad. Porque no hablamos solo de "delitos", sino del exceso en su realización: la persistencia en la agonía de quien será finalmente asesinado, la provocativa exhibición de la impunidad de los culpables, el gozo de quien mata, viola y mutila en el momento de perpetrar su acción. Pero esa evidencia se nos hace inverosímil; de ahí la inclusión en estas crónicas de advertencias como: “Todo lo aquí narrado ocurrió, aunque parezca increíble" (Turati 173) o “[esto] parecería irreal si no hubiera ocurrido en México" (203). Nuestra propia capacidad humana para perpetrar el mal se nos hace incomprensible; de ahí que nos cuestionemos: “¿Cómo pasa alguien de ser bravucón de barrio a multihomicida? ¿De qué pasta fueron hechos quienes, además de matar, firman con sadismo cuerpos ajenos? ¿Qué leche mamaron para compartir tal desprecio por la vida?" (Turati 38). Y, al fin, el despliegue impúdico del horror se nos vuelve insoportable, como insoportable es 
el dolor de las madres cuyos hijos han desaparecido, situación a la que nos asomamos con el caso de Mirna Nereyda, expuesto en la crónica “Donde pite el tren", de Javier Valdez (2017):

Dice que lo sueña: él, Roberto, no muy recio, por uno de los lados de la vía, con el rostro cubierto con no sabe qué, y diciéndole que lo alcance, que si lo alcanza va a decirle dónde está. Y ella corre y corre. Se quita las zapatillas, se pone los tenis. Se quita los tenis y se pone botas. Se descalza o usa huaraches. Y corre y corre y corre. Y él le dice, casi festivo, que lo alcance. Y ella se esfuerza, grita, llora y corre más. Y no. No lo alcanza. Y entonces despierta. Y con tal de verlo, cierra los ojos llorosos para seguirlo soñando.

Sueña otra vez. Son sueños recurrentes, que empiezan y empiezan, pero no terminan. Y se repiten con macabros y dolorosos caprichos. Encuéntrame, amá. Le dice él. Ven, encuéntrame. Dónde hijo. Aquí, amá. Aquí. Dónde. Donde pita el tren.

Y busca en La Constancia, La Esperanza, Mochicahui, San Blas y Tetamboca. Y vuelve a buscar. Pero no está. Y el tren no deja de pasar. (244)

El sueño adquiere aquí estatus de limbo, un espacio sin tiempo donde los familiares se aferran a sus muertos o desaparecidos, dejando su propia vida en suspenso. Al ser la búsqueda de los desaparecidos una actividad eminentemente femenina, las mujeres se vuelven "nuevas Lloronas" (Turati 205) quienes, en última instancia, como indica una de ellas, lo que buscan es vida: quizás no la de sus familiares, sino la de ellas mismas (Rea 272).

Esta continuidad entre sueño y vigilia se expresa en el propio entorno, que va adquiriendo en el relato una cualidad fantasmagórica. Leemos en Ni vivos ni muertos, de Federico Mastrogiovanni (2014): "La niebla envuelve la ciudad en una atmósfera al mismo tiempo irreal y un poco siniestra. El silencio es lo más sorprendente. Todo parece estar rodeado de algodón. Saltillo es un espejismo con su belleza austera y la niebla que se adueña de las calles" (s/p). Pero además se genera una alteración en la percepción de la realidad, que se expresa claramente en los comentarios de una de estas cronistas:

Soñé que me secuestraban. Llevaba a mi hija en mis brazos, envuelta en un rebozo, dormida. Me llevaban a un cuarto oscuro con paredes de piedra y me sentaban en una silla de 
metal, junto a una mesa de metal. Frente a mí, los hombres comenzaban a cavar una fosa. Yo abrazaba a mi hija y la cubría con mi cuerpo. Pensaba en Ricardo sin nosotras, buscándonos. Me aterraba ese pensamiento. Entonces, consciente dentro de mi sueño pensaba "esto es un sueño, esto no puede estar pasando porque estás soñando, vas a despertar y verás a Ricardo y a tu hija dormidos a tu lado, a salvo". Pero dentro del sueño también pensaba "esto sí puede estar pasando, Daniela. Tú sabes que está pasando. Tú lo sabes. La gente está desapareciendo". (Rea 259)

El recurso sirve para expresar tanto el desconcierto de víctimas como el estado de alteración en el que viven los victimarios. Así se inicia, precisamente, la reconocida investigación del periodista británico Ioan Grillo (2012), revelando de paso cómo en esta narrativa la violencia - la violencia de aquello que se relata, pero también del mismo hecho de "agredir" al lector con estas historias - tiene el efecto de devolverle su inicial potencia significativa a expresiones manidas y ya vacías:

Ahora todo parecía un mal sueño.

Había sido vívido y salvaje, de eso no cabía la menor duda, pero de algún modo parecía algo irreal, como si Gonzalo hubiera presenciado aquellas horribles escenas desde arriba, como si hubiera sido otro el que había cruzado disparos en plena luz del día con los policías cubiertos con pasamontañas. Otro el que había irrumpido violentamente en las casas y sacado a rastras a hombres inútilmente protegidos por esposas y madres que lloraban. Otro el que había atado de pies y manos a las víctimas con cinta adhesiva de seguridad para que recibieran golpes sin poder moverse de la silla y estuvieran días sin comer. Otro quien les había partido el cráneo a machetazos cuando aún estaban vivos.

Pero todo había sido real. (s/p)

Un último ejemplo de esta continuidad entre realidad y ficción lo encontramos en el testimonio de Alfredo de la Cruz, alias Pensamiento, uno de los sobrevivientes de la tragedia en la plataforma petrolífera de Usumacinta, Campeche, en 2009. Tras su recuperación, de la Cruz comenzó a notar que "se convertía en pez", ya que la piel se le endureció y se le volvió escamosa, para mudarla al tiempo. 
Pero si bien la piel de pescado se cayó de su cuerpo, a Pensamiento le quedaron las huellas del naufragio adheridas al alma. Uno de sus placeres era acostarse a dormir y disfrutar de los sueños, en los que aparecían su familia o los buenos momentos del día. Sin embargo, la furia del mar invadió ese territorio antes inexpugnable con lagunas, plataformas hundiéndose, cadáveres y marejadas. Una noche de noviembre, camino a Mérida, Pensamiento se alarmó cuando un pescado del tamaño de un hombre se atravesó en la carretera caminando sobre la cola. (en Ruiz Parra 87)

La psicología indica que dentro de la condición postraumática no es extraño el brote de episodios psicóticos que llevan al paciente a confundir realidad y ficción. En este sentido, la condición de la víctima puede llegar a parecerse mucho a lo ominoso, en tanto el recuerdo se inscribe en una representación anómala de lo conocido. El periodista Sergio González Rodríguez (2016) asoció esta sensibilidad a la anamorfosis, en tanto luego de que un suceso traumático quiebra la cotidianidad de la víctima, esta comienza a percibir lo que acontece desde una visión deformada:

[...] las ideas de tiempo y espacio se someten a un régimen inverso o perverso, origen de una arquitectura abyecta que altera los valores conocidos y establece una realidad de espacios contiguos, controlados y vigilados por el crimen organizado o las fuerzas armadas. [...] El ciudadano carece de certezas ante sí mismo y solo vive en el trance prolongado de la incertidumbre: el ambiente de fricción y de niebla. (250)

En tanto piedra angular de lo fantástico, lo ominoso marca la emergencia de aquello propio, familiar, que se ha mantenido oculto ("reprimido", en jerga psicoanalítica) y sin embargo irrumpe, tiñendo de extrañeza lo cotidiano (Freud 1919). El choque entre dos órdenes contrapuestos (real/irreal) deja de ser tal para quienes viven bajo el estrés constante de una guerra de baja intensidad (como es la que vive México desde el sexenio de Felipe Calderón); y sus límites se vuelven porosos e imprecisos. Pero, a diferencia de lo que ocurre en el relato fantástico, aquí no existe la solución de la huida: lo pesadillesco no radica en las jugarretas del inconsciente - lo onírico-, sino en la misma realidad. No tenemos la opción de elegir creer, como señalaba Todorov en su señero estudio sobre lo fantástico (1968), que todo aquello que nos perturba no es sino 
una ilusión de los sentidos, y que basta despertar para estar a salvo. Si lo ominoso es una atmósfera que permea lo "real", bien cabe reexaminar, a la luz de las nuevas circunstancias, sus estatutos y sus componentes.

\section{Para concluir}

Históricamente, hemos definido lo real desde un criterio alético fundado sobre lo posible y lo necesario, y que se expresa principalmente en tres ejes: el físico, el instrumental y el mental (Doležel 1998). Así, por ejemplo, en el mundo real es imposible que volvamos al pasado, porque no podemos retroceder en el tiempo; tampoco podemos estar en dos lugares simultáneamente, ni atravesar paredes. Sin embargo, a la luz de las historias que nos cuentan estas crónicas, parece pertinente cuestionar lo real ya no solo desde lo materialmente posible, sino también desde lo éticamente concebible. Nuestras reacciones primarias al leer historias reales de torturas, secuestros y abusos son elocuentes en este sentido: "no puede ser", "no es posible”, "jamás creí que alguien fuese capaz de..." o el manoseado: "la realidad supera a la ficción".

Pero no es que la realidad supere a la ficción: es que la realidad contiene más aristas, matices y recovecos de los que conocemos y/o estamos dispuestos a aceptar. En un nivel político, como argumenta Zavala, ello obedece a la connivencia de instituciones y personas para sacar rédito de una situación particular, maquillando o escondiendo los hechos, o bien, silenciando al periodismo (o anulando su capacidad de denuncia y fiscalización). La realidad, entonces, es distinta de la representación que disponemos de ella, porque existe una voluntad mancomunada, entre pequeños grupos de interés, por distorsionarla. Hay alguien que conoce la realidad y se esfuerza en maquillarla. Sin embargo, el problema no es únicamente epistemológico - como alega el ensayista mexicano- sino también ontológico. La dimensión moral de la violencia no anula su contenido político, sino que lo enraíza en una corriente universal en la cual la coyuntura densifica su significado. Desde aquí, por ejemplo, la crónica nos fuerza a reconocer nuestra propia disposición y capacidad humana para la crueldad: aquello que Kant (1792) comprendió como tentación, llamándolo "el mal radical" y que luego Arendt (1963) resignificaría situándolo dentro de la banalidad. Así podemos comprender el mal no solo como una intencionalidad, sino también como una atmósfera; un espíritu de época que cristaliza en una 
serie de actos violentos que muchas veces pueden tener una motivación clara y concreta, pero que en otros casos también pueden ser gratuitos e inconducentes. Como indica Berstein (2002) ambos "tipos" de mal —el radical y el banal- no son excluyentes.

Todo ello tiene dos consecuencias, que lejos de cerrar la reflexión aquí iniciada, la ramifican y proyectan. La primera es que, ante un periodismo narrativo de estas características, que remonta claramente a lo informativo, se hacen necesarias nuevas estrategias lectoras, así como nuevas formas de comprender lo periodístico (su función, pero también su importancia) en relación con el contexto en el cual se desarrolla. La denuncia y el develamiento de verdades ocultas tocan no solo a la dimensión racional del conocimiento, sino también a su aspecto emocional; en otras palabras, la información "pura y dura" puede proporcionarnos antecedentes valiosos para el entendimiento lógico y operativo, pero no genera de por sí la empatía necesaria para lograr una comprensión integral - humana- de una situación. A esto último es a lo que apunta la crónica narrativa, y eso es lo que justifica su uso de recursos narrativos y estilísticos propios de la literatura. El aspecto estético es consecuencia de la mirada y no es constitutivo, por sí solo, de lo "narrativo" o "literario" de este tipo de textos. Vale decir: una crónica no es "literaria" porque su autor utilice metáforas, juegue con los tiempos del relato o exhiba un dominio del lenguaje que va más allá de lo referencial; su espesor estético deriva de cierto enfoque hacia la realidad que se busca encuadrar, no hacia el texto, y ese enfoque suele estar regido por un criterio ético.

En este sentido, se hace necesario deslindar la espectacularización de la violencia - basada en la satisfacción del morbo y expresada, por ejemplo, en el sensacionalismo de la nota roja - para situar a esta crónica narrativa sobre la violencia en la línea de lo que José Ovejero (2012) ha llamado "textos crueles": aquellos que nos fuerzan a ver lo que preferiríamos obviar, generando desde esa incomodidad una reflexión ética y autocrítica. En términos estrictamente periodísticos, como ha hecho notar Damián Fernández Pedemonte (2001), los relatos respecto de la violencia cumplen un papel simbólico fundamental, ya que muestran las fisuras de la sociedad: "unos límites más allá de los cuales esta no se puede aventurar, las formas que puede asumir el mal" (117). Unos límites, agregaríamos, donde las consecuencias visibles de ese mal encarnan la contradicción entre la necesidad de contar y la imposibilidad 
de entender; entre la ferocidad de la evidencia y la dificultad de expresarla con palabras.

Ello nos lleva a la segunda consecuencia: al asentarse en lo que comprendemos por "realidad", el mismo criterio de lo fantástico amerita una revisión. Ya que los avances científicos y tecnológicos han modificado de manera sustancial nuestro criterio de lo posible, teóricos como David Roas (2011) han propuesto que la esencia del género radica no en la incertidumbre o la vacilación del lector ante lo narrado - que es lo que planteó Todorov - sino en la inexplicabilidad de los fenómenos que se relatan. Sin embargo, creemos que esa inexplicabilidad requiere al menos una precisión, ya que podemos referirla en términos causales o físicos (por ejemplo: es inexplicable que una persona esté al mismo tiempo en dos lugares distintos), pero también en un sentido ético o axiomático (por ejemplo: resulta inexplicable tanta barbarie). Nuestros criterios valóricos inciden de manera decisiva en lo que consideramos "real", "aceptable" o "posible"; tal como indicó el filósofo Hilary Putnam (1988): "el contenido de la misma noción de verdad depende de los criterios de aceptabilidad racional, y estos, a su vez, presuponen nuestros valores, sobre los que descansan" (s/p). En otros términos, ser racional no solo implica ser lógicos, sino también poseer un criterio de relevancia, en el cual están supuestos todos nuestros valores. De aquí que la consideración del componente ético sea necesaria a la hora de reexaminar conceptos como "real" y "fantástico", dentro de los márgenes de la literatura o fuera de ellos. Y más aún: esa necesidad se vuelve urgencia cuando vemos que en nuestro entorno el horror deja de ser algo excepcional ("extraño", "insólito", “impensable": todo aquello que acaba reduciéndose, explicándose y venciéndose en la ficción fantástica), y se vuelve parte de nuestra cotidianidad, naturalizándose y socavando poco a poco nuestra capacidad de asombro, espanto e indignación.

\section{Referencias bibliográficas}

Arendt, Hannah. Eichmann en Jerusalén. Santiago de Chile, Debolsillo, 2014 [1963].

Bersntein, Richard. El mal radical. Una indagación filosófica. Buenos Aires, Lilmod, 2005 [2002].

Caillois, Roger. Imágenes, imágenes... (sobre los poderes de la imaginación). Barcelona, Edhasa, 1970. 
Caparrós, Martín. La crónica. Madrid, Círculo de Tiza, 2015.

Carilla, Emilio. El cuento fantástico. Buenos Aires, Nova, 1968.

Doležel, Lubomir. Heterocósmica. Ficción y mundos posibles. Madrid, Arco Libros, 1998.

Fernández Pedemonte, Fabián. La violencia del relato. Discurso periodístico y casos policiales. Buenos Aires, La Crujía, 2001.

Freud, Sigmund. Lo siniestro. México, D.F., Letracierta, 1978 [1919].

Fuguet, Alberto. "Perdido (missing)". Apuntes autistas. Santiago de Chile, Aguilar, 2007, pp. 357-374.

González Rodríguez, Sergio. "Anamorfosis de la víctima”. Siete voces contra la impunidad. La ira de México. VVAA. México, D.F., Debate, 2016, pp. 125-146.

Grillo, Ioan. El narco. En el corazón de la insurgencia criminal mexicana. Barcelona, Urano, 2012. Versión electrónica MOBI/Kindle.

Jäger, Siegfred. “Discurso y conocimiento: aspectos teóricos y metodológicos de la crítica del discurso y del análisis de dispositivos". Métodos de análisis crítico del discurso. Comps. Ruth Wodak y Michael Meyer. Barcelona, Gedisa, 2003, pp. 61-100.

Kant, Immanuel. La religión dentro de los límites de la mera razón. Madrid, Alianza, 1986 [1792].

Kapuściński, Ryszard. El Sha o la desmesura del poder. Trad. Agata Orzeszek. Barcelona, Anagrama, 2006.

Lyotard, Jean Francoise. La posmodernidad (explicada a los niños). Barcelona, Gedisa, 1994.

Mastrogiovanni, Federico. Ni vivos ni muertos. La desaparición forzada en México como estrategia de terror. México, D.F., Grijalbo, 2014. Versión electrónica MOBI/Kindle.

Mauleón, Héctor de. Roja oscuridad. Crónica de días aciagos. México, D.F., Planeta, 2015.

Melchor, Fernanda. Aquí no es Miami. México, D.F., Random House, 2018.

Mouat, Francisco. El empampado Riquelme. Santiago de Chile, Lolita Editores, 2012 [2001].

Osorno, Diego Enrique. La guerra de los Zetas. Viaje por la frontera de la necropolítica. México, D.F., Debolsillo, 2012. 
Ovejero, José. La ética de la crueldad. Barcelona, Anagrama, 2012.

Poblete Alday, Patricia. "La crónica contemporánea: límites y abismos”. Hispamérica, no. 47, 2018, pp. 37-45.

Poniatowska, Elena. “Cantinflas”. Todo México, vol. II. México, D.F., Diana, 1995, pp. 175-181.

. La noche de Tlatelolco. Testimonios de historia oral. México, D.F., Era, 1971.

Putnam, Hilary. Razón, verdad e historia. Madrid, Tecnos, 1988. Versión electrónica MOBI/Kindle.

Ramos, Julio. Desencuentros de la modernidad en América Latina. Literatura y política en el siglo XIX. México, D.F., Fondo de Cultura Económica, 1989.

Rea, Daniela. Nadie les pidió perdón. Historias de impunidad y resistencia. México, D.F, Urano, 2015.

Roas, David. Tras los límites de lo real. Una definición de lo fantástico. Madrid, Páginas de Espuma, 2011.

Rotker, Susana. La invención de la crónica. México, D.F., Fondo de Cultura Económica-Fundación para un Nuevo Periodismo Iberoamericano, 2005.

Ruiz Parra, Emiliano. "El naufragio de las mandarinas". Siete voces contra la impunidad. La ira de México. VVAA. México, D.F., Debate, 2016, pp. 71-87.

Schmidt, Siefgred. "La auténtica ficción es que la realidad existe. Modelo constructivista de la realidad, la ficción y la literatura". Teorías de la ficción literaria. Comp. Antonio Garrido Domínguez. Madrid, Arco Libros, 1997, pp. 207-238.

Todorov, Tzvetan. Introducción a la literatura fantástica. Barcelona, Ed. Buenos Aires, 1982 [1968].

Turati, Marcela. Fuego cruzado. Las víctimas atrapadas en la guerra del narco. México, D.F., Grijalbo, 2011.

"Reportear desde el país de las fosas". Siete voces contra la impunidad. La ira de México. VVAA. México, D.F., Debate, 2016, pp. 169-194.

Valdez, Javier. Periodismo escrito con sangre. Selección, prólogo y notas de César Ramos. México, Aguilar, 2017. 
Warren, Carl. Géneros periodísticos informativos. Barcelona, Harper and Eow Publishers, 1975.

Zavala, Oswaldo. Los cárteles no existen. Narcotráfico y cultura en México. Barcelona, Malpaso, 2018. 